\title{
An Innovative Technique of Decompressive Craniectomy for Acute Ischemic Stroke
}

\author{
Marcelo M. Valença ${ }^{1}$, Carolina Martins², \\ Joacil Carlos da Silva1, Caio Max Félix Mendonça1, \\ Patrícia B. Ambrosi ${ }^{1}$ and Luciana P.A. Andrade-Valença ${ }^{1,3}$ \\ ${ }^{1}$ Neurology and Neurosurgery Unit, Federal University of Pernambuco, \\ ${ }^{1}$ Neurosurgery Unit, Hospital Esperança, \\ ${ }^{2}$ Medical School of Pernambuco Imip, \\ ${ }^{3}$ Neurology Unit, Medical School of the University of Pernambuco, \\ Recife, \\ Brazil
}

\section{Introduction}

Decompressive hemicraniectomy $(\mathrm{DH})$ is a lifesaving surgical procedure to arrest a rapidly rising intracranial pressure, not controllable with other methods. This procedure decreases the intracranial mass effect, reducing the risk of transtentorial herniation, therefore preventing secondary brain injury, brainstem compression and death.

Currently, malignant hemispheric infarction is one of the main indications for DH (Chen et al., 2006; Delashaw et al., 1990; Rengachary et al., 1981; Schwab et al., 1998; Merenda \& DeGeorgia, 2010) either when the intracranial hypertension does not respond to conservative therapies (i.e., osmotic therapy, hyperventilation, etc.); or when there is an important brain shift of the midline structures, or both (Gerriets et al., 2001).

It is estimated that about $10 \%$ to $20 \%$ of the patients with infarction in the territory of the middle cerebral artery (MCA) or of the internal carotid artery (ICA) develop hemispheric cerebral edema/swelling, presenting signs of uncal and cingulate herniations and neurological deterioration (Paciaroni et al., 2011; Minnerup et al., 2011; Thomalla et al., 2010; Paciaroni et al., 2011). Clinical deterioration of patients with massive MCA infarction (with or without additional involvement of anterior cerebral artery or posterior cerebral artery) is the result of brain edema, which peaks on days 3 to 5 , followed afterwards by progressive edema reduction within the following two weeks (Shaw et al., 1959; Merenda \& DeGeorgia, 2010; Ng \& Nimmannitya, 1970). This form of malignant cerebral infarction - often irresponsive to medical treatment - is associated with very high mortality rates (i.e. $70 \%$ to $90 \%$ of cases) (Jourdan et al., 1993; Rieke et al., 1995; Ropper, 1986; Moulin et al., 1985).

Decompressive surgery comprehends the surgical measures taken to arrest a rising intracranial pressure and can be divided into external and internal decompression - at times combined into a single procedure. External decompression involves removal of parts of 
calvaria and duraplasty. Internal decompression is the term used when removal of affected parts of the brain or cerebellum is performed to achieve stabilization of intracranial pressure.

Decompressive surgery has been used in a number of emergency settings as brain trauma (Britt \& Hamilton, 1978; Ransonhoff et al., 1971; Venes \& Collins, 1975), pseudotumor cerebri (Martin \& Corbett, 1996), encephalitis (Taferner et al., 2001), cerebral venous thrombosis (Valença et al., 2009), severe lead encephalopathy (McLaurin \& Nichols, 1957), and Reye's syndrome (Ausman et al., 1976). The use of DH has also been reported in the treatment of acute rupture of cerebral aneurysms (Fisher CM, Ojemann, 1994; Mitka, 2001).

\section{Decompressive craniectomy - historical note}

The idea of opening the skull to relieve pressure is an old concept. It was exemplified in the Greek myth of Athena, goddess of wisdom, according to Hesiod in the poem Theogony (circa $700 \mathrm{BC}$ ). Zeus, the supreme god of Olympus, after swallowing his first wife Metis, had a severe and progressively worsening headache attributed to the growth of his daughter Athena inside his skull. Hephaestus, the god of fire and metalwork, struck Zeus' head with an axe splitting his cranium in order to alleviate his pain, and Athena was born through this primitive craniotomy (Brasiliense et al., 2010).

Trepanation has been performed since the Mesolithic Era, before the development of metal instruments and written language. There is widespread archaeological evidence from South America, Europe, Asia and Africa documenting this ritualistic skull opening as long as 10.000 B.C. (Marino \& Gonzales-Portillo, 2000; Martin, 1995, Missios, 2007).

The ancient Egyptians performed trephinations with local anesthesia, prepared by mixing ground marble with vinegar. The success of these procedures is evidenced by the discovery of healed wounds in skulls unearthed from tombs dating back 6000 years. On the tomb of Bany Hassan, there are paintings that depict a surgeon performing cranial surgery with the patient seated (El Gindi, 2002).

The pre-conquest South America nations were extremely skilled in the art of opening the skull. Operations were apparently performed for trauma, fractures, diseases of the cranium, scalp and cranial infections, epilepsy, headaches, mental disease, and some thaumaturgic rituals. The main archaeological findings related to trephination are associated with excavations in the territories of the Paracas, Nazca, Huari, and Içá cultures. They were less popular in the more recent Inca culture and were apparently forbidden in the Inca Empire long before the Hispanic conquest (Marino \& Gonzales-Portillo, 2000).

The written description and codification of trepanation began in Greece during the fifth century B.C. Hippocrates, in his work On Injuries of the Head, described the different types of skull fractures and provided specific instructions as well as warnings on the use and dangers of trepanation (Martin, 2000).

Galen of Pergamon (A.D. 129-200) lived in an era when trepanation was better known and more widely accepted by practicing physicians as well as the public. He advocated use of the procedure for relief of intracranial pressure and drainage of phlegmatous lesions (Missios, 2007). 
After the collapse of Roman Empire, medical knowledge was preserved by Middle Eastern cultures. The most famous representative author or this period was Ibn Sina or Avicenna (A.D. 980-1037); although he was well versed in intracranial anatomy, his contributions on cranial surgery are mostly speculative (Sarrafzadeh et al., 2001).

The practice of surgery in the Middle Ages was well described by a less well-known author called Serefeddin Sanbuncuoglu (A.D. 1385-1468?), the author of Cerrahiyyetü l-Haniyye (Imperial Surgery), which was written in Turkish in 1465. The book contains wonderful color illustrations of craniotomy procedures (Elmaci, 2000).

Berengario da Carpi (1460-1530) wrote the most important work on craniocerebral surgery of the Renaissance Period, the Tractatus de Fractura Calvae sive Cranei (Treatise on Fractures of the Calvaria or Cranium), in which he described an entire set of surgical instruments to be used for cranial operations to treat head traumas, which became a reference for a later generation of physicians (Di leva et al., 2011).

The modern concept of decompressive surgery was born with the statement of Kocher, in 1901: "If there's no CSF pressure, but brain pressure exists, then pressure relief must be achieved by opening the skull." This author introduced the concept of elevated intracranial pressure as a global phenomenon requiring a large skull opening to be treated (Gautschi \& Hildebrandt, 2009).

Harvey Cushing designed a standard subtemporal decompressive craniectomy largely used during his huge neurosurgical series with highly impressive results (Cushing, 1905).

Despite its sporadic use for trauma and other conditions characterized by elevated ICP, decompressive surgery was not routinely employed until the 1990s. Probably the initial poor results when used in patients without Intensive Care Unit (ICU) support led some authors to abandon the procedure. As stated by Clarke in 1968: "The reason for reporting this experience is to warn others from doing similar surgery" (Clark et al., 1968).

The landmark work of Guerra and colleagues (1999) described their results using decompressive craniectomy for traumatic brain swelling. The good results from this series established the procedure as an appropriate therapy for refractory intracranial pressure of any origin (Guerra et al., 1999).

Decompressive craniectomy for cerebral ischemia was seldom indicated. Ivamoto, in 1974, reported the first clinical series, but with no great repercussions (Ivamoto et al., 1974). However, after the definition of the "malignant" MCA territorial infarction, which courses with dramatic intracranial hypertension, there has been a number of experimental and clinical studies on the benefits of early decompression of the brain during ischemic events (Hacke et al., 1996).

Finally the scientific evidence of mortality reduction demonstrated by three randomized trials has made decompressive surgery part of the modern arsenal for treatment of ischemic stroke (Vahedi et al., 2007).

\section{Decompressive hemicraniectomy for cerebral hemispheric ischemic lesions}

The better results obtained after DH in patients with hemispheric lesions (e.g. stroke), when compared with patients with severe brain trauma, could be explained by the fact that lesions 
in unconscious patients after trauma are usually diffuse rather than restricted, as is the case of an unilateral cerebral hemispheric lesion, such as MCA ischemia.

\subsection{When we should perform a decompressive hemicraniectomy?}

Decompressive hemicraniectomy in cerebral hemispheric ischemia is a lifesaving procedure that should be used without delay when the intracranial hypertension does not respond to conservative therapies (i.e., osmotic therapy, hyperventilation, etc.); or when there is an important brain shift of the midline structures, or both, in a symptomatic patient with motor deficit and impairment of consciousness. In a previous healthy patient with no severe cognitive deficit the age of the patient (e.g. $>75$ years of age) or side of the lesion (left sided lesion in a right handed patient) does not contraindicate the procedure (Merenda \& DeGeorgia, 2010).

In such a setting, the immediate removal of the bone corrects the cerebral displacement, relieving the pressure exerted on the rostral midbrain structures. In theory, DH may also improve perfusion of the collateral leptomeningeal vessels, improve retrograde perfusion of MCA, optimize perfusion of the penumbra, and, consequently reduce the size of the infarct and neurological deficit, even in the absence of a brainstem deformation or uncal compression. Uncal and cingulate herniations may cause secondary vascular compressions. During the development of a cingulate (subfalcine) herniation, the cingulate gyrus shifts across and under the falx cerebri and it may compress the anterior cerebral artery, cutting off the blood supply to normal brain areas. Uncal herniation, likewise, causes cistern obliteration and may compress the posterior cerebral artery. The neurological repercussions caused by an uncal herniation (a subtype of transtentorial herniation) due to a MCA territory infarction depends on the degree of brain and brainstem atrophy, intracranial volume reserve (subaracnoid space/CSF) and the type of variation of the tentorial aperture.

Since the works of Sunderland (1958) and Corsellis (1958) a relationship between the notch size/shape and patterns of uncal herniations was recognized. In this regard, Adler and Milhorat (2002) studied 100 human autopsy cases (23 female cadavers) and derived from data related to the maximum notch width and notch length, they classified the specimen tentorial apertures as: narrow $(15 \%)$, wide $(12 \%)$, short $(8 \%)$, long $(15 \%)$, typical $(24 \%)$, large $(9 \%)$, small $(10 \%)$, and mixed $(7 \%)$. Accordingly, patients with a wide tentorial notch (i.e. maximum notch width $>32 \mathrm{~mm}$ ) ( Adler \& Milhorat, 2002) and a considerable space between the brainstem and the free tentorial edge have a lower chance of brainstem compression by cerebral tissue herniation.

Furthermore, the territory irrigated by the MCA is variable and the volume of ischemic area after occlusion of M1 segment of the MCA is unpredictable, it depends on the extension of collateral circulations (mainly those supplied by the anterior cerebral artery and posterior cerebral artery).

There are predictive signs of MCA malignant infarction observed on CT-scan (performed within 12 hours of ictus), such as: (1) hypodensity in more than $50 \%$ of the MCA territory, (2) hyperdense MCA, and (3) diffuse attenuation between the cortex and the white matter. In addition, MRI findings with diffusion weighted imaging signals occupying $>89 \mathrm{ml}$ volume is $90 \%$ sensitive and $96 \%$ specific in predict malignant cerebral hemispheric infarction (Arenillas et al., 2002). 
In a prospective cohort of 1,010 patients with acute ischemic stroke, Paciaroni and associates (2011) observed an incidence of hyperdense MCA and/or ICA arteries of about 15\%, which was associated with a final infarct involving more than one third of the MCA territory and poor functional outcome at 3 months. Overall, 163 patients $(16.1 \%)$ had a final infarct covering more than one third of the MCA territory. $52.7 \%$ of the individuals with hyperdense MCA and/or ICA had an infarct involving more than one third of the MCA territory compared to only $9.9 \%$ of the patients without artery hyperdensity. At 3 months, 18 patients were lost to follow-up, 325 patients (32.8\%) were disabled and 165 died (16.5\%). The following factors were associated with unfavorable outcome: age, NIH Stroke Scale score for 1 added point on admission, stroke due to atherosclerosis, hemorrhagic transformation of the ischemic lesion, and hyperdense MCA and/or ICA (OR 2.0, 95\% CI 1.0-4.0).

\section{Initial NIH Stroke Scale (NIHSS) score at least 20 for dominant stroke}

2. NIHSS score at least 15 for nondominant stroke

3.Younger age

4. Early hypodensity $>50 \%$ of the MCA territory, including the basal ganglia

5. Additional involvement of ipsilateral ACA or PCA territories

6. CT-documented anteroseptal shift $>5 \mathrm{~mm}$

7. CT-documented pineal shift $>2 \mathrm{~mm}$

8. Volume of $\geq 145 \mathrm{ml}$ on DWI MRI

Fig. 1. Clinical and neuroradiological features predictive of a malignant course after a middle cerebral artery (MCA) infarction. ACA, anterior cerebral artery; PCA, posterior cerebral artery.

Recent study (Minnerup et al., 2011), enrolling 52 ischemic stroke patients with carotid-T or MCA main stem occlusion and ischemia (reduced cerebral blood volume) on perfusion CT performed on admission, showed that $26(50 \%)$ of them developed malignant MCA infarction. Two subgroups were separated according to the development of malignant MCA infarction defined by clinical signs of herniation. Age, a decreased level of consciousness on admission, cerebral blood volume (CBV) lesion volume, CSF volume, and the ratio of CBV lesion volume to CSF volume were significantly different between malignant and 
nonmalignant subgroups. The best predictor of a malignant course was the ratio of CBV lesion volume to CSF volume.

Merenda and DeGeorgia (2010) cited a number of clinical and neuroradiological features that appear to be predictive of a malignant course after MCA infarction, as illustrated in Figure 1. Although, a significant number of patients presenting predictors of malignant course may not develop fatal brain swelling (Merenda \& DeGeorgia, 2010).

\subsection{The classic decompressive craniectomy}

The technical recommendations for the performance of DH stress that craniectomy should be performed in the frontotempoparietal region, reaching the base of the frontal bone and sparing the calvarium $\approx 1 \mathrm{~cm}$ from the midline to prevent injury to bridging veins and additional bleeding (Wagner et al., 2001). A diameter of around or above $12 \mathrm{~cm}$ is desirable, as it has been shown that doubling the diameter from 6 to $12 \mathrm{~cm}$ results in an increase in decompressive volume from 9 to $86 \mathrm{~cm}$ (Wirtz et al., 1997; Wagner et al., 2001). The bone removal towards the occipital squama adds little to the decompressive procedure itself, as the falx prevents the medial incursion of cerebrum in this region and has a constant length of approximately $6 \mathrm{~cm}$ (Rhoton Jr \& Ono, 1996), besides, it might produce problems of stability and patient positioning (Wagner et al., 2001).

\subsection{Duraplasty}

It is estimated that only $15 \%$ reduction is achieved with craniectomy alone and duraplasty may decrease intracranial pressure by an additional 55\% (Chen et al., 2006). Consequently, a generous duraplasty would cause significant intracranial pressure reduction. Usually a planed, large skin incision, allows for sufficient quantities of pericranium to be used as a dural graft and this has resulted in lower deep wound infection rates (5\%) than when foreign material was used (e.g. neuro-patch, 15\%) (Malliti et al., 2004), Additionally, CSF leaks were more frequent in the neuro-patch group of patients $(13 \%$ vs. $1.6 \%)$. Synthetic dural grafts should therefore be reserved for situations when autologous grafts are not sufficient or unavailable.

\subsection{Disadvantages and secondary problems following decompressive craniectomy}

As HD increased in popularity among surgeons as a life-saving treatment of malignant intracranial hypertension following a vascular insult or brain trauma, reports on its technical execution and potential complications have been appearing in the literature. Among them are hemorrhagic complications, overindication, problems with flap storage and sterilization, metabolic changes associated with lack of bony covering, syndrome of the trephined, hydrocephalus and others (Chen et al., 2006; Valença et al., 2009; Faleiro et al., 2008).

\subsection{Hemorragic complications}

Parenchymal hemorrhages and infarcts, secondary to the initial site of ischemia, and associated with the hemicraniectomy occurred with high frequency rates (Wagner et al., 2001). An increasing risk of mortality is also linked to hemicraniectomy-associated bleeding. 
This hemicraniectomy-associated bleeding is related to the size of the craniectomy performed, that is to say, the smaller the hemicraniectomy, the more often lesions will occur. The mechanism leading to hemicraniectomy-associated lesions involves the shear forces at the edges of the trephination. Small craniectomies cause a higher shear stress on the swollen brain, particularly if the craniectomy edges are sharp.

Creation of vascular channels to reduce the risk of vascular congestion in the herniated tissue, thereby decreasing the secondary injury caused by the craniectomy was a procedure designed by Csókay and coworks (2002) to decrease the brain lesion induced by the classic decompressive hemicraniectomy.

\subsection{Increased brain edema}

After vascular occlusion brain water content increases, reaching its maximum 2-4 days later (O'Brien \& Waltz, 1973) and significant changes in blood brain barrier may occur for 20 days (O’Brien et al., 1974). Thus, we can subdivided the brain swelling in stroke in three phases: (1) an immediate increase (within first minute) in brain volume due to vasoparalysis (tissue acidosis); (2) a metabolic (cytotoxic) type of brain edema; and (3) a vasogenic brain edema which follows the metabolic type of edema after 4-6 hours, reaching its maximum after a few days. In about 3-4 days after cerebral arterial occlusion it is detected the maximal anatomic brain deformity, and it is only after this period of time that a gradual reabsortion of the excessive parenchymal fluid takes place (Hossmann \& Schuier, 1979; Ayata \& Ropper, 2002; Valença et al., 2009b; Shaw et al., 1959).

In addition, the combination of reperfusion and hemicraniectomy experimentally caused an increase in brain edema and breakdown of the blood-brain barrier, although a decrease in the infarction size was observed (Engelhorn et al., 2003). Comparable results were obtained by Cooper and colleagues (1979) in edema induced by cold in dogs, with edema volume seven times larger in craniectomized animals. Since the driving force in edema pathophysiology is the pressure gradient across the injured capillaries, cerebral decompression may decrease interstitial fluid pressure and, as a result, increase edema formation. In this regard, craniectomy caused a significant decline in tissue pressure in the cortical gray matter in cat models (Hatashita et al., 1985), a phenomenon that probably occurs after decompressive craniectomy in a patient with brain infarction caused by traumatic vessel occlusion, who had a poor outcome (Venes \& Collins, 1975). This increased edema can lead to higher shear forces and contribute to hemicraniectomy-associated lesions.

\subsection{Flap storage and sterilization}

The gradual acceptance of decompressive craniectomy as a therapeutic tool in a selected, but significant number of patients with stroke or intracranial hypertension will result in an increased demand for cranioplastic procedures with its inherent costs.

During classic decompressive hemicraniectomy procedure, the bony flap is removed and stored under the abdominal fat or in a freezer. The replacement of the bone or cranioplasty is performed after the resolution of the hemispheric swelling, which occurs six to 20 weeks later, in surviving patients. The storage of the a large bony flap under the abdominal fat is time-consuming procedure and very probably is a cause of moderate to severe abdominal 
pain, not infrequently associated with sizeable hematomas. Infection may occur, as well. It is well-know that increase in the intracranial pressure is the result of pain and agitation, thus this is another disadvantage of storing the bone in the abdominal subcutaneous tissue. On the other hand, bone resorption may be high (up to 50\%) after cryopreservation (Grant et al., 2004).

Autoclaving the bone flap and sterilization with ethylene oxide were also tried. Missori and coworkers (2003) repositioned the bone after an average period of 4.3 months in 16 patients in whom the bone flap was removed for decompressive craniectomy, washed in hydrogen peroxide and then placed in hermetically-sealed bags and sterilized using ethylene oxide. The authors reported that, after an average follow-up of 20 months, the esthetic and functional results were good in 15 patients (Missori et al., 2003).

Autoclaving the bone flap is another option to be used (Jankowitz \& Kondziolka, 2006; Osawa et al., 2000, Vanaclocha et al., 1997). Biopsies of the tumor invaded bone flaps autoclaved for 20 minutes at 134 degrees $C$ and $1 \mathrm{~kg} / \mathrm{cm}^{2}$ and re-implanted showed newly formed bone partly re-populated by osteocytes. After studied 6 cases the authors concluded that autoclaved calvarial bone, when replaced with direct contact with living bone, will be gradually repopulated with osteocytes (Vanaclocha et al., 1997). In this regard, we believe that an alternative that may increase the re-population rate of bone flaps that underwent autoclave sterilization is to reintroduce bone cells (e.g. osteoclasts and osteoblasts), using fresh bone powder or stem cells, into perforations made in the craniotomy flap to be replaced.

\subsection{Overindication}

In 1995, Rieke and colleagues reported the first prospective study with the use of DH in space-occupying supratentorial infarction, obtaining a significant benefit with the combination of bone removal and dural patch enlargement. Subsequently, Schwab and associates (1998) demonstrated that if the patients were submitted to decompressive surgery within the first 24 hours (even before any significant brain shift of the midline structures), a further reduction in mortality rates to $16 \%$ occur. The remaining question is: do all patients with early (predictive) clinical/neuroimaging signs of malignant cerebral infarction require $\mathrm{DH}$ for the correction of intracranial hypertension?

False-positive classification as malignant infarction is of major concern as it may result in unnecessary surgical treatment, while a high threshold for indicating this procedure may severely compromise results.

Although this question does not have an answer at this point, it is our feeling that performance of a decompressive surgery, using a technique that allows the bony flap to open gradually, according to the intracranial pressure (Valença et al., 2009), would be a less harmful alternative to some patients, since, in the absence of a gradual mass effect, the flap would stay in a normal anatomic position, while absent flap problems and metabolic changes due to lack of bone covering would be prevented. Moreover, a decompressive surgery may improve perfusion of the collateral leptomeningeal vessels, optimizing perfusion of the penumbra regions. 


\subsection{Syndrome of trephined}

As a larger-sized hemicraniectomy is desirable to prevent complications related to insufficient decompression (Stiver, 2009), the number of problems related to a sinking defect might be expected to increase.

The "syndrome of the trephined" or "sinking skin flap syndrome" (Stiver, 2009; Winkler et al., 2000) involves the occurrence of severe headache, convulsion, dizziness, undue fatigability, poor memory, irritability, and intolerance to vibration. The syndrome of the sinking skin flap has been related to the action of atmospheric pressure and changes in hydrostatic pressure of cerebrospinal fluid (CSF), and those have been shown to resolve after cranioplasty.

It is known that skull defects are associated with a blood flow decrease related to postural changes, suggesting that $\mathrm{DH}$ has an impact on dynamic cerebral blood flow regulation. Cranioplasty affects postural blood flow regulation, cerebrovascular reserve capacity and cerebral glucose metabolism (Winkler et al., 2000). These effects were associated with a clinical improvement in all patients except in those whose cranioplasty was delayed for a long time following the HD. Therefore early cranioplasty or a decompressive surgery which uses a technique that allows the bony flap to be kept in place and open gradually, according to the intracranial pressure is desirable to facilitate rehabilitation in patients after decompressive surgery (e.g. "window-like” craniotomy) (Valença et al., 2009).

\subsection{Hydrocephalus}

Hydrocephalus is also a common complication after DH, especially in trauma (Stiver, 2009). Its causes are multiple, but absence of a bone flap causes major disturbance to the intracranial pressure regulatory mechanisms. As a result of the lower intracranial pressure, CSF absorption may be deficient, since a pressure gradient between CSF and the venous blood is required for this to happen.

Again, a decompressive surgery which uses a technique that allows the bony flap to be kept in place and open gradually, according to the intracranial pressure would result in sooner reestablishment of intracranial biomechanical conditions. If such an assumption is correct, a lower incidence of hydrocephalus would be expected with the use of our proposed "window-like"craniotomy procedure (Valença et al., 2009).

\section{4. "Window-like"craniotomy versus classic decompressive craniectomy}

Although DH has led to a substantial decline in mortality rates, several problems remained to be solved. Many of them resulted from the lack of bony covering and the changes associated with it. A decompressive surgery that used a technique allowing the bony flaps to be open gradually depending on the intracranial pressure would theoretically sort out many of the problems related to DH (Valença et al., 2009).

The idea of performing an "window-like" craniotomy as an alternative to substitute decompressive hemicraniectomy was reported in 2003 (Valença \& Valença, 2003). In 2009 we published our results with a series of cases (Valença et al., 2009), emphasizing the advantages of the new procedure over the classic decompressive hemicraniectomy (Figure 2). 


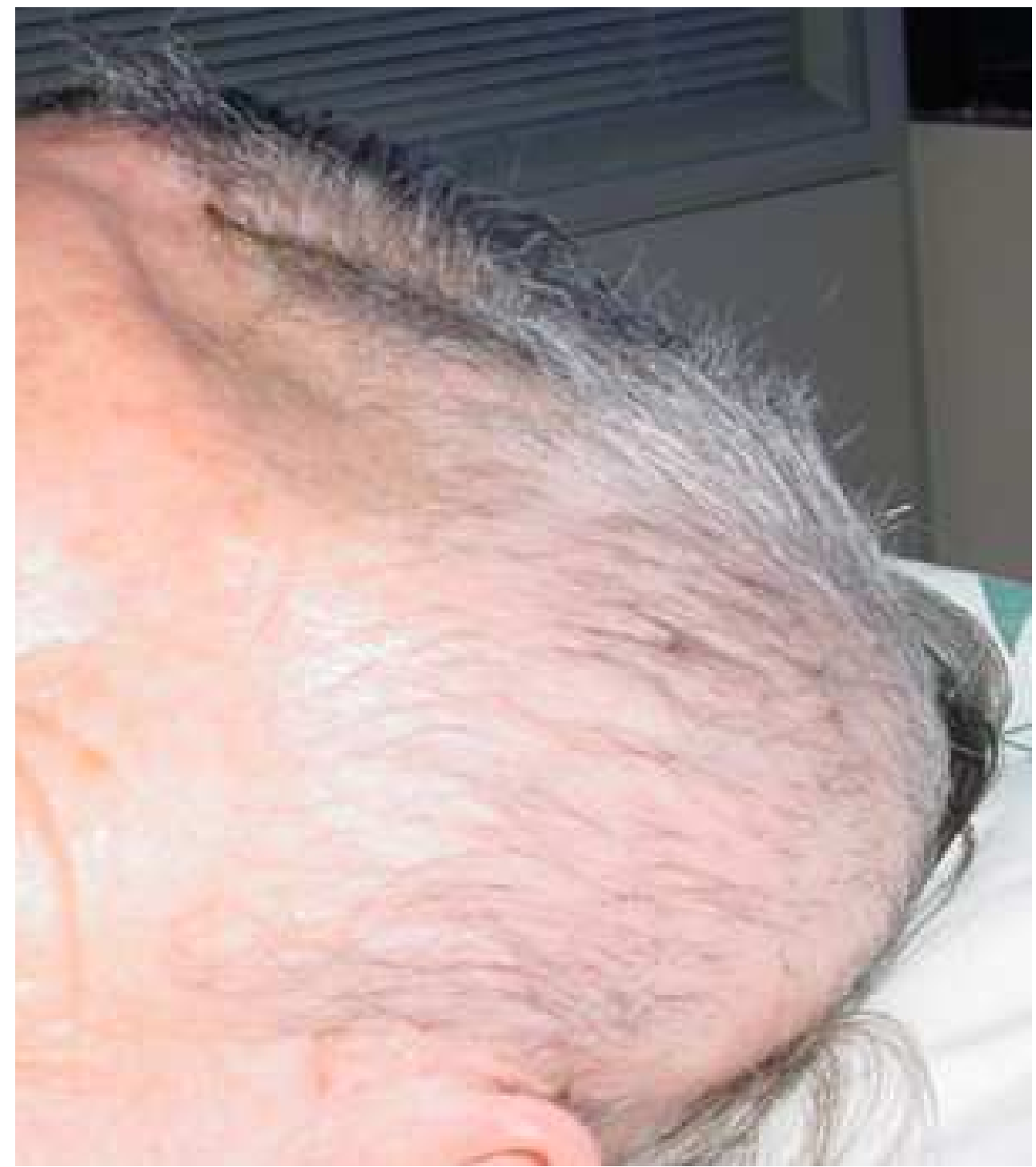

Fig. 2. The classic decompressive craniectomy, which causes trephine syndrome.

\section{5. "Window-like" craniotomy: Surgical technique}

The surgical procedure involves a large semicircular skin incision starting in the proximities of the midline and extending to the posterior parietal area, ending at the level of the tragus. The scalp must be elevated from the underlying pericranium to ensure greater elasticity and a looser skin flap to allow the stitching up of the skin at the end of the "windowlike" operation, covering again the bone with the skin. 
An extensive, near rectangular-shaped craniotomy is performed involving frontal, temporal, and parietal bones, and part of the occipital squama (diameter $12-15 \mathrm{~cm}$ ). The angle of the bone cut must be beveled outwards to allow the upper part of the craniotomy bone flap to rest on the adjacent skull and prevent penetration into the intracranial cavity. An anterior temporal craniectomy (subtemporal decompression) is added to relieve temporal lobe pressure (Figure 3). Dural incisions are performed and the dura is fixed at the bone border to prevent epidural bleeding (Valença et al., 2009).

Using a vertical cut, the bone flap is divided into two similarly sized pieces, which will be the opening of the "window lids". The outer frontal and parietooccipital sides of the flap are each one tied to the skull at two points (see arrows in Figure 4) using a synthetic nonabsorbable suture (i.e. polypropylene) to function as a hinge joint that allows opening of the window but prevents downward movement of the bone inside the skull. We advise inserting sutures at the edges of the bone flap in such a way that the lateral portion of the window is divided into three parts (Figures 3 and 4).

The recommended beveling of the craniotomy edges is important in the upper part of the craniotomy. What may prevent the bone from sinking in, besides the above-mentioned aspect, are the following: 1 . the underlying attached dura mater; therefore, the dura-bone stitches should be placed $0.5 \mathrm{~cm}$ from the bone edge. 2. a good alignment of the bone flaps with the calvarium; 3 . the intracranial pressure; and 4. the fact that the close of the bone "window" and the cranial vault reconstruction follow the principles used in the construction of vaults (a semicircular arch-shaped structure) where many segments are held in place by lateral thrust (representing the calvarium where the bone flaps will be fixated, Figure 3). The anterior and posterior parts of the craniotomy - the suture placement - should be cut vertically in order to permit a good alignment of the bone flaps with the calvarium. Thus, the central, bisected portion of the bone does not "sink in" when the brain later atrophies after infarct or major trauma (Valença et al., 2009). In our experience we have seen a good aesthetic result as early as 2-3 months following the procedure, although a foreseeable defect at the edge and along the central vertical line of the craniotomy can be felt on palpation.

After 5 months of follow-up the appearance of the "window-like" craniotomy was similar to that of a normal classical "fixated" craniotomy, with no signs of movement of the partially free bone flaps.

A dura patch, using synthetic graft, lyophilized cadaver dura mater, pericardium, or homologous pericranium, fascia lata or temporal fascia is placed in the incision $(\sim 13-20 \mathrm{~cm}$ in length and 4-8 cm wide). The bone flap is divided into two similar-size pieces by a vertical cut, which will be the opening of the "window lids". The outer frontal and parietooccipital sides of the flap are tied to the skull at 2 points, to function as a hinge joint that allows the opening of the window but prevents the bone from moving downward inside the skull.

A number of difficulties are encountered when performing the duraplasty using the stellar durotomy. In order to facilitate the duraplasty we have developed a new form of dural closure resembling an anteroposterior bridge between the dural edges (Valença et al., 2009). The dura mater is opened in a way that resembles two semicircular "ears" with the bases facing the upper and lower bone boundaries, respectively. On the anterior and posterior 
limits of the craniotomy $1 \mathrm{~cm}$ of dura mater is left in order to permit a subsequent suture of the rectangular dural graft.

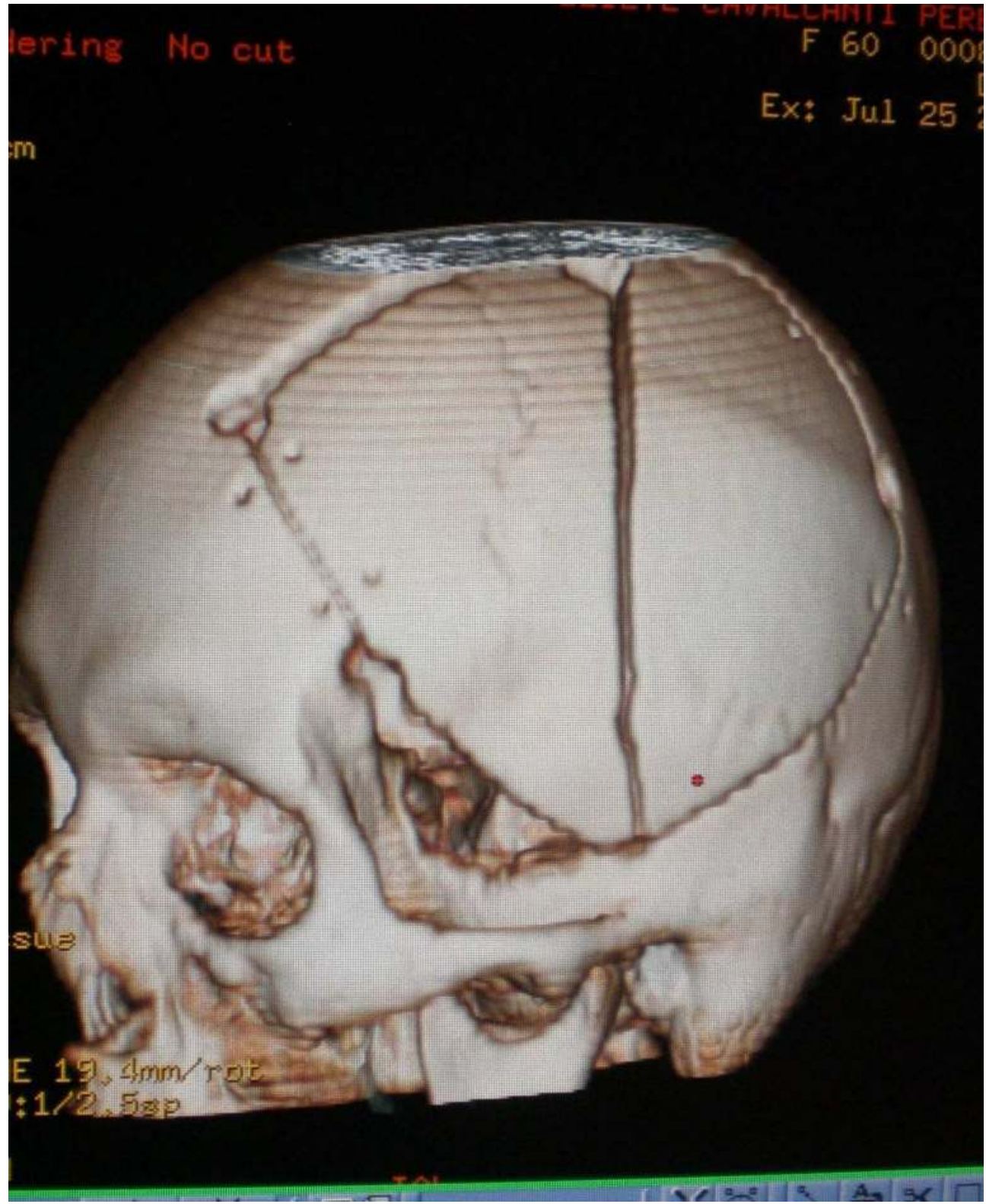

Fig. 3. CT-scan showing the anterior temporal craniectomy and the "window-like" craniotomy after 3 months of the procedure. 


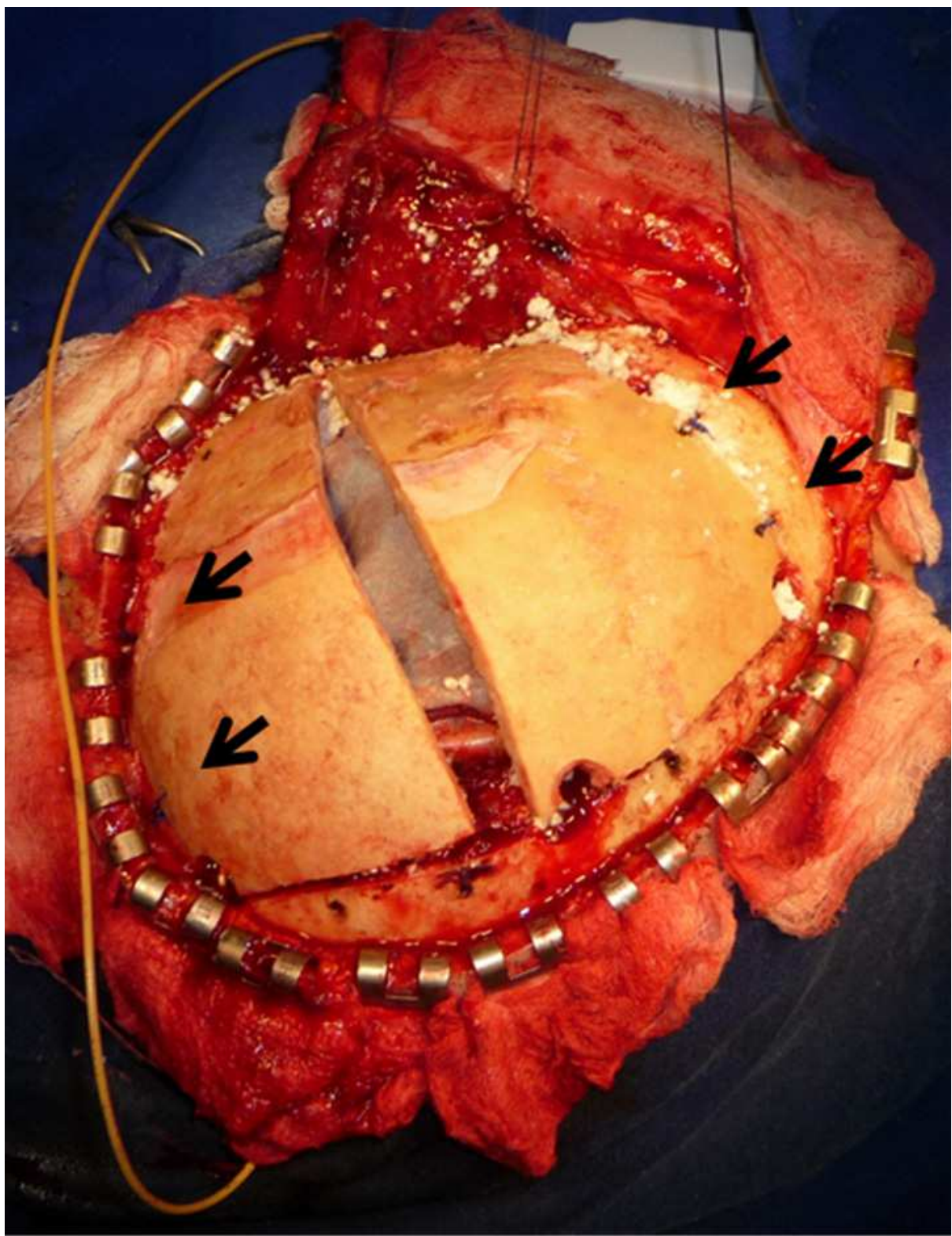

Fig. 4. Left side "window-like" craniotomy. The outer frontal and parietooccipital sides of the flap are each one tied to the skull at two points (see arrows) using a synthetic nonabsorbable suture to function as a hinge joint that allows opening of the window but prevents downward movement of the bone inside the skull. We advise inserting sutures at the edges of the bone flap in such a way that the lateral portion of the window is divided into three parts. 


\section{Advantages of decompressive surgery, using a technique that allows the bony flap to open gradually, according to the intracranial pressure}

The proposal of decompressive surgery using a craniotomy in an "window-like" fashion presents the following advantages: (i) it allows the edematous cerebral parenchyma to herniate with a gradual opening, simultaneously relieving the elevated intracranial pressure; (ii) it is an anatomic option that preserves the brain-skull biomechanics and avoids the use of expensive bio-prosthetic materials; (iii) it may avoid the development of sinking skin flap symptoms; (iv) it obviates the need for a second bone-replacement surgical procedure at a later stage, which may have an impact on the overall treatment cost; (v) it is not necessary the storage of a large bony flap under the abdominal fat, a procedure that is time-consuming and is cause of moderate to severe abdominal pain (pain causes agitation thereby increasing intra-abdominal and intracranial pressures), sometime associated with sizeable hematomas and infection; (vi) probably there is an attenuation in the formation of brain edema because the procedure may allow pressure at the herniated tissues close to normal levels with the presence of the bone flap.

The "window-like" procedure allows the performance of a large hemicraniectomy to adequately decompress the ischemic brain and avoid hemicraniectomy-associated lesions. At the same time, it offers an anatomic, inexpensive solution that allows the gradual accommodation of the herniated brain tissue, with a decrease in the intracranial pressure after brain insult. This surgical treatment may avoid edge trauma and ischemia, since the transcalvarial (external) herniation may be directed more uniformly towards the center of the craniotomy by the angle formed between the skull and the partially opened bone flaps. Again, the principle of the window-like craniotomy prescribed here mimics the opening of the sutures observed in child hydrocephalus. On the other hand, by recomposing a resistant barrier between the brain and the environment, it possibly prevents the sinking flap symptoms that detract from the functional outcome. A comparable procedure - hinge craniotomy - was recently described (Schmidt et al., 2007).

As to whether a young survivor could resume sports after the "window-like" procedure, we still lack sufficient evidence to confidently state that after one year the bone has healed sufficiently to allow sporting activities, we believe that such activities can be recommended without the need for further surgery to stabilize the bone. However, to be certain of this, further studies are required to clearly demonstrate bone resistance sufficient to sustain significant impacts, not only in the case of the procedure presented here but also after the subsequent repositioning of the bone to correct the defect left by a conventional decompressive hemicraniectomy, since bone resorption might occur (Stiver, 2009, Faleiro et al., 2008).

The "window-like" craniotomy was used by us in eight patients with malignant ischemic stroke with no mortality. None of these patients develop hydrocephalus and the aesthetic result was good.

\section{Future perspectives}

Present results indicate that, despite adequately addressing several drawbacks of the conventional DH, "window-like" techniques for DH will benefit further from observations 
of clinical practice. From a technical stand-point the technique might be improved by the development of two devices: (a) a hinge and (b) a synthetic dura mater substitute in the form of an ellipsoid "bag" rather than the commercial available rectangular graft (Valença et al., 2009). Although this second device could save time during duroplasty, it can only be acceptable if it presents complication rates similar or smaller than using pericranium grafts.

We reported (Valenca et al., 2009) the possibility of using metal hinges to replace the synthetic nonabsorbable sutures. To this end, the hinges ( 2 on each side of the craniotomy) should be fixed into the calvaria and to the bone flaps by using screws. The metallic implants must be compatible with the use of MR imaging. The opening must be situated toward the outer calvaria, a kind of hinge designed to lock the bone flaps in a natural anatomical position (horizontal plane), thus preventing the central portion of the bone from sinking in when the brain later atrophies.

Using the same rational to develop the idea of the "window-like" craniotomy, we recently use a similar approach to substitute the bifrontal decompressive craniectomy. The one-piece bifrontal craniotomy is tied to the skull posteriorly at two points, allowing the opening of the bone flap in a fashion similar to a "car hoop" (car hood decompressive craniotomy). We used this procedure with success in two occasions: a man with severe brain trauma with diffuse bifrontal contusion and a patient with a large fronto-basal meningeoma with significant brain edema. The "car hood" procedure may be useful in patients with bilateral infarction involving the anterior cerebral arteries, particularly in those with occlusion of a dominant A1.

\section{Conclusion}

Decompressive craniectomy in cerebral ischemia is a lifesaving procedure. The history of the development of this treatment, its indications, the techniques available to perform the procedure, its expected results and complications were discussed. Alternative procedures to the classic decompressive hemicraniectomy, including "window-like" craniotomy, were presented. Decompressive surgery, using a technique that allows the bony flap to open gradually, according to the intracranial pressure, adds the advantage of avoiding a second surgical procedure to close the bone defect, therefore preventing the metabolic cerebral impairment associated with lack of the overlying skull.

In conclusion, the present proposal of decompressive surgery using a craniotomy in an "window-like" fashion presents the following advantages: (i) it allows the edematous cerebral parenchyma to herniate with a gradual opening, simultaneously relieving the elevated intracranial pressure; (ii) it is an anatomic option that preserves the brain-skull biomechanics and avoids the use of expensive bio-prosthetic materials; (iii) it may avoid the development of sinking skin flap symptoms; (iv) it obviates the need for a second bonereplacement surgical procedure at a later stage, which may have an impact on the overall treatment cost.

\section{References}

Adler DE, Milhorat TH (2002) The tentorial notch: anatomical variation, morphometric analysis, and classification in 100 human autopsy cases. Journal of Neurosurgery 96:1103-1112 
Arenillas JF, Rovira A, Molina CA, Grivé E, Montaner J, Alvarez-Sabín J. Prediction of early neurological deterioration using diffusion- and perfusion-weighted imaging in hyperacute middle cerebral artery ischemic stroke. Stroke. 2002 Sep;33(9):2197-203.

Ausman JI, Rogers C, Sharp HL: Decompressive craniectomy for the encephalopathy of Reye's syndrome. Surg Neurol 6:97-99, 1976

Ayata C, Ropper AH. Ischaemic brain oedema. J Clin Neurosci 2002;9:113-124.

Brasiliense LB, Safavi-Abbasi S, Crawford NR, Spetzler RF, Theodore N. The legacy of Hephaestus: the first craniotomy. Neurosurgery. 2010 Oct;67(4):881-4; discussion 4.

Britt RH, Hamilton RD. Large decompressive craniotomy in treatment of acute subdural hematoma. Neurosurgery 2:195-200, 1978

Chen C, Smith ER, Ogilvy CS, Carter BS. Decompressive craniectomy: physiologic rationale, clinical indications, and surgical considerations. In: Schmidek \& Sweet Operative Neurosurgical Techniques: Indications, Methods, and Results. Elsevier, Philadelphia, 70-80, 2006

Clark K, Nash TM, Hutchison GC. The failure of circumferential craniotomy in acute traumatic cerebral swelling. J Neurosurg. 1968 Oct;29(4):367-71.

Corsellis JAN. Individual variation in the size of the tentorial opening. J Neurol Neurosurg Psychiatry 21:279-283, 1958

Csókay A, Együd L, Nagy L, Pataki G: Vascular tunnel creation to improve the efficacy of decompressive craniotomy in post-traumatic cerebral edema and ischemic stroke. Surg Neurol 57:126-129, 2002

Cooper PR, Hagler H, Clark WK, Barnett P. Enhancement of experimental cerebral edema after decompressive craniectomy: implications for the management of severe head injuries. Neurosurgery. 1979;4:296-300

Cushing $\mathrm{H}$. The stablishment of cerebral hernia as a decompressive measure for inaccessible brain tumor; with the description of intramuscular methods of making the bone defect in temporal and occipital regions. Surg Gynecol Obstet. 1905;1:297-314.

Delashaw JB, Broaddus WC, Kassel NF, Haley EC, Pendleton GA, Vollmer DG, Maggio WW: Treatment of right hemispheric cerebral infarction by hemicraniectomy. Stroke 21:874-881, 1990

Di Ieva A, Gaetani P, Matula C, Sherif C, Skopec M, Tschabitscher M. Berengario da Carpi: a pioneer in neurotraumatology. J Neurosurg. 2011 May;114(5):1461-70.

El Gindi S. Neurosurgery in Egypt: past, present, and future-from pyramids to radiosurgery. Neurosurgery. 2002 Sep;51(3):789-95; discussion 95-6.

Elmaci I. Color illustrations and neurosurgical techniques of Serefeddin Sabuncuoglu in the 15th century. Neurosurgery. 2000 Oct;47(4):951-4; discussion 4-5.

Engelhorn T, Doerfler A, de Crespigny A, Beaulieu C, Forsting M, Moseley ME. Multilocal magnetic resonance perfusion mapping comparing the cerebral hemodynamic effects of decompressive craniectomy versus reperfusion in experimental acute hemispheric stroke in rats. Neurosci Lett. 2003;344:127-31

Faleiro RM, Faleiro LC, Caetano E, Gomide I, Pita C, Coelho G, Brás E, Carvalho B, Gusmão SN. Decompressive craniotomy: prognostic factors and complications in 89 patients. Arq Neuropsiquiatr. 2008 Jun;66(2B):369-73. 
Gautschi OP, Hildebrandt G. Emil Theodor Kocher (25/8/1841-27/7/1917)--A Swiss neurosurgeon and Nobel Prize winner. Br J Neurosurg. 2009 Jun;23(3):234-6.

Gerriets T, Stolz E, König S, Babacan S, Fiss I, Jauss M, Kaps M: Sonographic monitoring of midline shift in space-occupying stroke. Stroke 32:442-, 2001

Grant GA, Jolley M, Ellenbogen RG, Roberts TS, Gruss JR, Loeser JD. Failure of autologous bone-assisted cranioplasty following decompressive craniectomy in children and adolescents. J Neurosurg. 2004 Feb;100(2 Suppl Pediatrics):163-8.

Guerra WK, Gaab MR, Dietz H, Mueller JU, Piek J, Fritsch MJ. Surgical decompression for traumatic brain swelling: indications and results. J Neurosurg. 1999 Feb;90(2):18796.

Fisher CM, Ojemann RG: Bilateral decompressive craniectomy for worsening coma in acute subarachnoid hemorrhage. Observations in support of the procedure. Surg Neurol 41:65-74, 1994

Hossmann K-A, Schuier FJ. Metabolic (cytotoxic) type of brain edema following middle cerebral artery occlusion in cats. In Price TR, Nelson E (eds). Cerebrovascular diseases. New York: Raven Press 1979:141-165.

Jankowitz BT, Kondziolka DS. When the bone flap hits the floor.Neurosurgery. 2006 Sep;59(3):585-90; discussion 585-90.

Jourdan C, Convert J, Mottolese C, Bachour E, Gharbi S, Artu F: Evaluation of the clinical benefit of decompression hemicraniectomy in intracranial hypertension not controlled by medical treatment. Neurochirurgie 39:304-310, 1993

Ivamoto HS, Numoto M, Donaghy RM. Surgical decompression for cerebral and cerebellar infarcts. Stroke. 1974 May-Jun;5(3):365-70.

Hacke W, Schwab S, Horn M, Spranger M, De Georgia M, von Kummer R. 'Malignant' middle cerebral artery territory infarction: clinical course and prognostic signs. Arch Neurol. 1996 Apr;53(4):309-15.

Hatashita S, Koike J, Sonokawa T, Ishii S. Cerebral edema associated with craniectomy and arterial hypertension. Stroke 16:661-668, 1985

Malliti M, Page P, Gury C, Chomette E, Nataf F, Roux FX. Comparison of deep wound infection rates using a synthetic dural substitute (neuro-patch) or pericranium graft for dural closure: a clinical review of 1 year. Neurosurgery 54:599-603; discussion 603-604, 2004

Marino R, Jr., Gonzales-Portillo M. Preconquest Peruvian neurosurgeons: a study of Inca and pre-Columbian trephination and the art of medicine in ancient Peru. Neurosurgery. 2000 Oct;47(4):940-50.

Martin G. Trepanation in the South pacific. J Clin Neurosci. 1995 Jul;2(3):257-64.

Martin G. Was Hippocrates a beginner at trepanning and where did he learn? J Clin Neurosci. 2000 Nov;7(6):500-2.

Martin TJ, Corbett JJ: Pseudotumor cerebri, in Youmans JR (ed): Neurological Surgery, $4^{\text {th }}$ ed . Philadelphia: WB Saunders, vol 4, pp 2980-2997, 1996

McLaurin RL, Nichols JB Jr: Extensive cranial decompression in the treatment of severe lead encephalopathy. Pediatrics 20:653-667, 1957

Minnerup J, Wersching H, Ringelstein EB, Heindel W, Niederstadt T, Schilling M, Schäbitz WR, Kemmling A. Prediction of Malignant Middle Cerebral Artery Infarction 
Using Computed Tomography-Based Intracranial Volume Reserve Measurements. Stroke. 2011 Sep 8. [Epub ahead of print]

Merenda A, DeGeorgia M. (2010). Craniectomy for acute ischemic stroke: how to apply the data to the bedside. Current Opinion in Neurology, vol 23, pp. 53-58

Missios S. Hippocrates, Galen, and the uses of trepanation in the ancient classical world. Neurosurg Focus. 2007;23(1):E11.

Missori P, Polli FM, Rastelli E, Baiocchi P, Artizzu S, Rocchi G, Salvati M, Paolini S, Delfini R. Ethylene oxide sterilization of autologous bone flaps following decompressive craniectomy. Acta Neurochir (Wien). 2003 Oct;145(10):899-902; discussion 902-3.

Mitka M. Hemicraniectomy improves outcomes for patients with ruptured brain aneurysms. JAMA 2001; 286:2084

Moulin DE, Lo R, Chiang J, Barnett HJM: Prognosis in middle cerebral artery occlusion. Stroke 16:282-284, 1985

$\mathrm{Ng} \mathrm{L,} \mathrm{Nimmannitya} \mathrm{J:} \mathrm{Massive} \mathrm{cerebral} \mathrm{infarction} \mathrm{with} \mathrm{severe} \mathrm{brain} \mathrm{swelling:} \mathrm{A}$ clinicopathological study. Stroke 1:158-163, 1970

O’Brien MD, Waltz AG. Transorbital approach for occluding the middle cerebral artery without craniectomy. Stroke 1973;4:201-206.

O’Brien MD, Jordan MM, Waltz AG. Ischemic cerebral edema and the blood-brain barrier. Distributions of pertechnetate, albumin, sodium and antipyrine in brains of cats after occlusion of the middle cerebral artery. Arch Neurol 1974;30:461-465.

Osawa M, Hara H, Ichinose Y, Koyama T, Kobayashi S, Sugita Y. Cranioplasty with a frozen and autoclaved bone flap. Acta Neurochir (Wien). 1990;102(1-2):38-41.

Paciaroni M, Agnelli G, Floridi P, Alberti A, Acciarresi M, Venti M, Alagia MG, Fiacca A, Gallina MC, Guercini G, Pantaleoni R, Leone F, Pieroni A, Caso V. Hyperdense Middle Cerebral and/or Internal Carotid Arteries in Acute Ischemic Stroke: Rate, Predictive Factors and Influence on Clinical Outcome. Cerebrovasc Dis. 2011 Aug 23;32(3):239-245. [Epub ahead of print]

Rengachary SS, Batnistsky S, Morantz RA, Arjunan K, Jeffries B. Hemicraniectomy for acute massive cerebral infarction. Neurosurgery 8:321-328, 1981

Ransonhoff J, Benjamin MV, Gage EL Jr, Epstein F. Hemicraniectomy in the management of acute subdural hematoma. J Neurosurgery 34:70-76, 1971

Rieke K, Schwab S, Krieger D, von Kummer R, Aschoff A, Schuchardt V, Hacke W: Decompressive surgery in space-occupying hemispheric infarction: Results of an open, prospective trial. Critical Care Medicine 23:1576-1587, 1995

Rhoton Jr AL, Ono M. Microsurgical anatomy of the region of the tentorial incisura. In: Wilkins Rh, Rengachary SS (ed): Neurosurgery. 2nd Ed, Vol. 1, New York, McGrawHill, 897-915, 1996

Ropper AH. Lateral displacement of the brain and level of consciousness in patients with an acute hemispheral mass. N Engl J Med 314:953-958, 1986

Sanderland S. The tentorial notch and complication produced by herniations of the brain through that aperture. Br J Surg 45: 422-438, 1958

Sarrafzadeh AS, Sarafian N, von Gladiss A, Unterberg AW, Lanksch WR. Ibn Sina (Avicenna). Historical note. Neurosurg Focus. 2001;11(2):E5.41 
Schmidt JH 3rd, Reyes BJ, Fischer R, Flaherty SK. Use of hinge craniotomy for cerebral decompression. Technical note. J Neurosurg107(3):678-82, 2007

Schwab S, Steiner T, Aschoff A, Schwarz S, Steiner HH, Jansen O, Hacke W. Early hemicraniectomy in patients with complete middle cerebral artery infarction. Stroke 29:1888-1893, 1998

Shaw CM, Alvord EC, Berry GR: Swelling of the brain following ischemic infarction with arterial occlusion. Arch Neurol 1:161-177, 1959

Stiver SI. Complications of decompressive craniectomy for traumatic brain injury. Neurosurg Focus 26 (6):E7, 2009

Taferner E, Pfausler B, Kofler A, Spiss H, Engelhardt K, Kampfl A, Schutzhard E: Craniectomy in severe, life-threatening encephalitis: a report on outcome and longterm prognosis of four cases. Intensive Care Med 27:1426-1428, 2001

Thomalla G, Hartmann F, Juettler E, Singer OC, Lehnhardt FG, Köhrmann M, Kersten JF, Krützelmann A, Humpich MC, Sobesky J, Gerloff C, Villringer A, Fiehler J, Neumann-Haefelin T, Schellinger PD, Röther J; Clinical Trial Net of the German Competence Network Stroke. Prediction of malignant middle cerebral artery infarction by magnetic resonance imaging within 6 hours of symptom onset: A prospective multicenter observational study. Ann Neurol. 68(4):435-45, 2010

Turney TM, Garraway WM, Whisnant JP: The natural history of hemispheric and brain stem infarctions in Rochester, Minnesota. Stroke 15:790-794, 1984

Vahedi K, Hofmeijer J, Juettler E, Vicaut E, George B, Algra A, et al. Early decompressive surgery in malignant infarction of the middle cerebral artery: a pooled analysis of three randomised controlled trials. Lancet Neurol. 2007 Mar;6(3):215-22.

Valença MM, Martins C, da Silva JC. "Window-like" craniotomy and "bridgelike" duraplasty: an alternative to decompressive hemicraniectomy. J Neurosurg. 2010 Nov;113(5):982-9. Epub 2009 Dec 11.

Valença MM, Valenca LPAA, Gonçalves da Silva G, Antunes-Rodrigues J, Leite JP. Postischemic stroke first-time seizures: influence of gender and age of the patient on the latent period. Neurobiologia (Recife) 72:27-32, 2009b

Valença MM, Valença LPAA. (2003) Doenças Cerebrovasculares, In Neurologia Clínica, edited by Gilson Edmar Gonçalves e Silva; Marco Otávio Saraiva Valença, 340-369. Ed. Universitária da UFPE, Recife

Vanaclocha V, Sáiz-Sapena N, García-Casasola C, De Alava E. Cranioplasty with autogenous autoclaved calvarial bone flap in the cases of tumoural invasion. Acta Neurochir (Wien). 1997;139(10):970-6.

Venes JL, Collins WF: Bifrontal decompressive craniectomy in the management of head trauma. J Neurosurgery 42:429-433, 1975

Wagner S, Schnippering H, Aschoff A, Koziol J, Schwab S, Steiner T. Suboptimum hemicraniectomy as a cause of additional cerebral lesions in patients with malignant infarction of the middle cerebral artery. J Neurosurgery 94:693-696, 2001

Winkler PA, Stummer W, Linke R, Krishnan KG, Tatsch K. Influence of cranioplasty on postural blood flow regulation, cerebrovascular reserve capacity, and cerebral glucose metabolism. J Neurosurg 93:53-61, 2000 
Wirtz CR, Steiner T, Aschoff A, et al. Hemicraniectomy with dural augmentation in medically uncontrollable hemispheric infarction. Neurosurgical Focus 2 (5):Article 3, 1997 


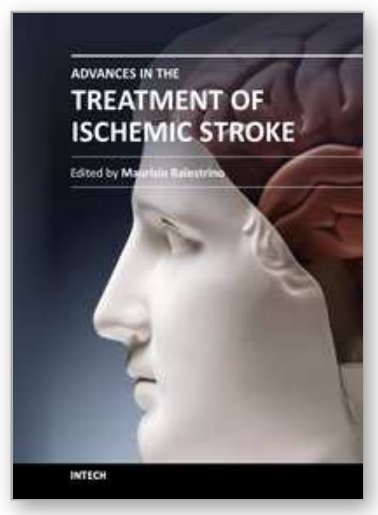

\author{
Advances in the Treatment of Ischemic Stroke \\ Edited by Dr. Maurizio Balestrino
}

ISBN 978-953-51-0136-9

Hard cover, 246 pages

Publisher InTech

Published online 02, March, 2012

Published in print edition March, 2012

In recent years research on ischemic stroke has developed powerful therapeutic tools. The novel frontiers of stem cells therapy and of hypothermia have been explored, and novel brain repair mechanisms have been discovered. Limits to intravenous thrombolysis have been advanced and powerful endovascular tools have been put at the clinicians' disposal. Surgical decompression in malignant stroke has significantly improved the prognosis of this often fatal condition. This book includes contributions from scientists active in this innovative research. Stroke physicians, students, nurses and technicians will hopefully use it as a tool of continuing medical education to update their knowledge in this rapidly changing field.

\title{
How to reference
}

In order to correctly reference this scholarly work, feel free to copy and paste the following:

Marcelo M. Valença, Carolina Martins, Joacil Carlos da Silva, Caio Max Félix Mendonça, Patrícia B. Ambrosi and Luciana P.A. Andrade-Valença (2012). An Innovative Technique of Decompressive Craniectomy for Acute Ischemic Stroke, Advances in the Treatment of Ischemic Stroke, Dr. Maurizio Balestrino (Ed.), ISBN: 978-95351-0136-9, InTech, Available from: http://www.intechopen.com/books/advances-in-the-treatment-of-ischemicstroke/decompressive-craniectomy-for-cerebral-ischemia

\section{INTECH}

open science | open minds

\section{InTech Europe}

University Campus STeP Ri

Slavka Krautzeka 83/A

51000 Rijeka, Croatia

Phone: +385 (51) 770447

Fax: +385 (51) 686166

www.intechopen.com

\section{InTech China}

Unit 405, Office Block, Hotel Equatorial Shanghai

No.65, Yan An Road (West), Shanghai, 200040, China 中国上海市延安西路65号上海国际贵都大饭店办公楼 405 单元

Phone: +86-21-62489820

Fax: $+86-21-62489821$ 
(C) 2012 The Author(s). Licensee IntechOpen. This is an open access article distributed under the terms of the Creative Commons Attribution 3.0 License, which permits unrestricted use, distribution, and reproduction in any medium, provided the original work is properly cited. 